\title{
MENENTUKAN MINIMUM SPANNING TREE MENGGUNAKAN ALGORITMA MODIFIKASI DARI ALGORITMA PRIM DAN KRUSKAL DALAM PERENCANAAN RUTE WISATA YANG EFISIEN
}

\section{DETERMINING MINIMUM SPANNING TREE BY USING MODIFICATION ALGORITHM OF PRIM AND KRUSKAL ALGORITHM IN EFFICIENT TOURISM ROUTE PLANNING}

\author{
Afrianti*, Effendi, dan Des Welyyanti \\ 1) Jurusan Matematika, Fakultas Matematika dan Ilmu Pengetahuan Alam Universitas Andalas, Kampus \\ Unand Limau Manis, Padang - Indonesia, 25163 \\ **antia376@gmail.com
}

\begin{abstract}
The use of an algorithm in determining the minimum spanning tree can also be implemented on a tourism object. Nowadays, efficiency has become an important thing in various aspects including traveling and determining the route of the places you want to visit. In its planning, the route should be efficient so that many tourism objects can be visited in a short time vacation. To determine the minimum spanning tree, the algorithm used in this study is the modified algorithm of prim and cruscal algorithm using the concept of hamiltonian path.

Keywords Minimun spanning tree, Prim algorithm, Kruskal algorithm, Modification algorithm, Hamiltonian path.
\end{abstract}

\begin{abstract}
ABSTRAK
Penggunaan suatu algoritma dalam menentukan minimum spanning tree juga dapat di implementasikan pada suatu objek wisata. Dewasa ini efisiensi adalah hal yang terpenting dalam berbagai aspek termasuk dalam berwisata dan penentuan rute tempat-tempat yang ingin di kunjungi. Dalam perencanaannya rute yang dibentuk haruslah efisien agar liburan dalam waktu yang singkat dapat mengunjungi banyak tempat wisata. Untuk menentukan minimum spanning tree pada penelitian ini, algoritma yang digunakan yaitu algoritma modifikasi dari algoritma prim dan algoritma kruskal yang menggunakan konsep hamiltonian path
\end{abstract}

Kata kunci: Minimum spanning tree, algoritma prim, algoritma kruskal, algoritma modifikasi, hamiltonian path

\section{PENDAHULUAN}

Perkembangan ilmu pengetahuan dan teknologi tidak terlepas dari peranan ilmu matematika. Teori graf merupakan salah satu cabang dari ilmu matematika yang membahas tentang berbagai jenis graf yang dapat diaplikasikan untuk memecahkan masalah dalam kehidupan sehari-hari.

Konsep-konsep pemecahan masalah graf muncul ketika beberapa masalah yang berkaitan dengan graf ditemukan dalam kehidupan nyata. Salah satunya adalah konsep 
tree. Konsep tree mampu mendukung pemecahan masalah dalam berbagai terapan graf, seperti spanning tree. Apabila spanning tree diterapkan pada persoalan yang mengandung unsur pencarian bobot yang minimum maka dinamakan minimum spanning tree.

Beberapa penelitian tentang penggunaan suatu algoritma untuk menentukan minimum spanning tree dan implementasinya pada suatu graf yang telah dilakukan diantaranya: Algoritma optimasi korelasi silang dinormalisasi berdasarkan minimum spanning tree telah dikaji oleh Changying et al (2019). Algoritma Hybrid dari algoritma genetik dan minimum spanning tree untuk penempatan PMU yang optimal telah dikaji oleh Devi et al (2020). Penerapan algoritma Greedy dalam menentukan minimum spanning trees pada optimisasi jaringan listrik jala, telah dikaji oleh Didiharyono et al (2018). Sari et al (2013) mengkaji implementasi algoritma genetika pada masalah TSP. Cahya ningsih et al (2013) mengkaji penerapan algoritma semut pada masalah TSP. Implementasi minimum spanning tree dalam menentukan prioritas pemeliharaan jalur jalan kota dengan biaya minimal dikaji oleh Djafar et al (2011). Minimum spanning tree pada jaringan pendistribusian aneka kripik Abdi Mulya di Kabupaten Grobogan di kaji oleh Rahmawati (2015). Selanjutnya, mengaplikasikan algoritma Prim untuk menentukan minimum spanning tree suatu graf berbobot dengan menggunakan pemograman berorientasi objek dilakukan Nugraha (2011).

Penggunaan algoritma Prim dan algoritma Kruskal dalam menentukan minimum spanning tree jika diimplementasikan pada suatu objek wisata untuk menentukan rute yang efisien, maka ada kemungkinan wisatawan melakukan perjalanan yang bolak balik, maka dari itu penulis melakukan modifikasi terhadap kedua algoritma tersebut dengan menggunakan konsep hamiltonian path. Hamiltonian path adalah lintasan yang melewati semua simpul di dalam graf tepat satu kali, sehingga wisatawan dapat mengunjungi semua tempat wisata yang ada tanpa harus mengunjungi lagi objek wisata yang pernah dikunjunginya.

\section{METODOLOGI}

Metode penelitian merupakan cara yang digunakan peneliti secara sistematis dalam menyusun sebuah penelitian. Pada penelitian ini langkah-langkah yang dilakukan penulis 
adalah merumuskan masalah, batasan masalah, tujuan penelitian, dan melakukan analisis terhadap hasil yang diperoleh dalam penelitian, selanjutnya penarikan kesimpulan.

Langkah-langkah yang dijabarkan sebagai berikut:

1. Merumuskan masalah. Permasalahan yang akan dikaji dalam penelitian ini adalah menentukan minimum spanning tree dari suatu objek wisata dengan menggunakan algoritma modifikasi dari algoritma Prim dan algoritma Kruskal.

2. Batasan masalah. Masalah yang akan dikaji dalam penelitian ini dibatasi pada penentuan minimum spanning tree dari suatu objek wisata dengan menggunakan algoritma modifikasi dengan menggunakan konsep hamiltonian path.

3. Tujuan yang ingin dicapai dalam penelitian ini adalah menentukan minimum spanning tree menggunakan modifikasi algoritma Prim dan algoritma Kruskal dalam perencanaan rute wisata yang efisien.

4. Melakukan analisis terhadap hasil. Dalam melakukan analisis dan pemecahan masalah dilakukan langkah-langkah sebagai berikut:

a. Merepresentasikan peta suatu objek wisata menjadi suatu graf, dimana objek wisata direpresentasikan sebagai simpul dan jalan yang menghubungkan antar objek wisata direpresentasi sebagai sisi serta jarak antar objek wisata direpresentasikan sebagai bobot.

b. Mencari minimum spanning tree dari graf tersebut dengan menggunakan algoritma modifikasi

\section{PEMBAHASAN}

Pada penelitian ini dibuat suatu algoritma baru, yaitu algoritma modifikasi. Algoritma modifikasi ini merupakan suatu algoritma yang dibuat menggunakan ide dari algoritma Prim dan algoritma Kruskal. Yang di modifikasi dari algoritma Prim dan Kruskal yaitu pada langkah pertama, pada algoritma Prim langkah pertama memilih simpul sebarang, dan pada algoritma Kruskal langkah pertama mengurutkan bobot dari sisi yang terkecil, sedangkan pada algoritma modifikasi memilih simpul yang berderajat minimum dan menggunakan konsep hamiltonian path.

Langkah pertama dimulai dari memilih satu simpul yang berderajat minimum, kemudian dilanjutkan dengan memilih sisi terdekat dengan simpul yang memiliki bobot terkecil. Apabila sisi yang dipilih membentuk siklus atau melewati simpul yang sudah 
dilewati, maka proses dibatalkan. Proses ini akan berulang sebanyak $n-1$ sisi dengan $n$ merupakan banyaknya simpul.

Langkah - langkah dalam algoritma modifikasi sebagai berikut:

1. Pilih satu simpul $v_{1}$ yang mempunyai derajat minimum. Jika terdapat simpul yang berderajat minimum lebih dari satu simpul maka tentukan minimum spanning tree dari setiap simpulnya kemudian pilih rute yang lebih optimal

2. Pilih sisi dalam $G$ yang berbobot minimum yang bersisian dengan simpul di $v_{1}$, masukkan kedalam pohon $T$. Jika terdapat lebih dari satu sisi yang berbobot sama dan minimum maka tentukan minimum spanning tree dari setiap kemungkinan kemudian pilih rute yang optimal.

3. Pilih sisi dari $G$ yang memiliki bobot minimum dan bersisian dengan simpul di $T$, dengan syarat sisi tersebut tidak membentuk siklus.

4. Jika $G$ memiliki $n$ simpul, berhenti setelah $n-1$ sisi dipilih.

Berikut ini adalah contoh graf yang akan digunakan untuk menentukan minimum spanning tree menggunakan algoritma modifikasi.

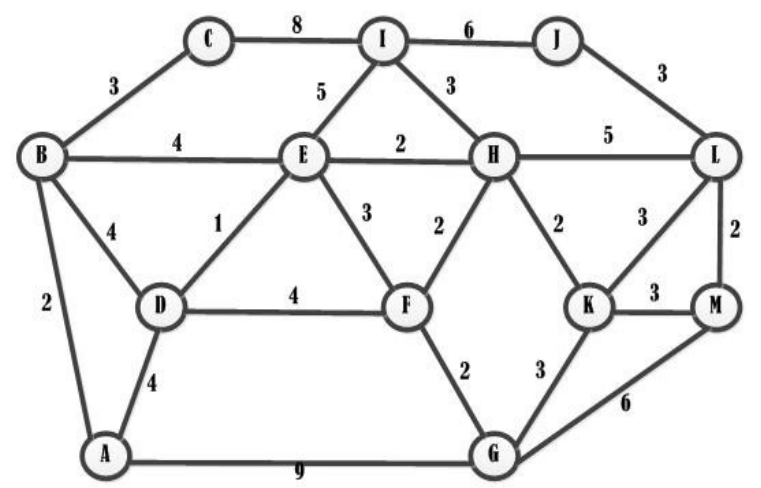

Gambar 3.1. Contoh graf untuk algoritma modifikasi

Akan ditentukan minimum spanning tree dari graf di atas dengan menggunakan algorima modifikasi, dengan langkah-langkah sebagai berikut.

1. Pilih simpul yang berderajat minimum, yaitu simpul $C$

2. Memilih sisi dalam $G$ yang mempunyai bobot minimum yang bersisian dengan simpul di $v_{1}$, masukkan kedalam pohon $T$. Sisi $C B$ dengan bobot 3 maka spanning tree yang dibentuk adalah 


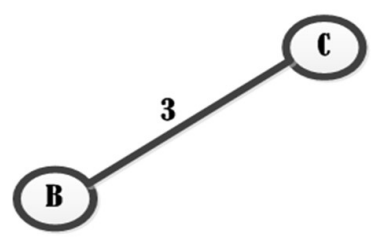

Gambar 3. 2. Langkah 2 untuk Gambar 3.1

3. Memilih sisi dari $G$ yang memiliki bobot minimum dan bersisian dengan simpul di $T$, dengan syarat sisi tersebut tidak membentuk siklus. Sisi $B A$ dengan bobot 2 maka spanning tree yang dibentuk adalah

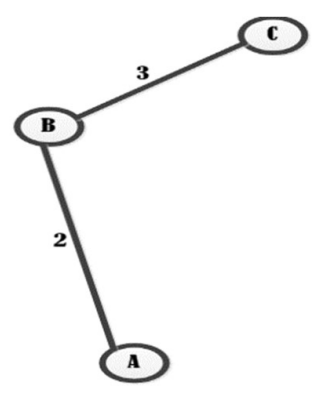

Gambar 3.3. Langkah 3 untuk Gambar 3.1

4. Sisi $A D$ dengan bobot 4 maka spanning tree yang dibentuk adalah

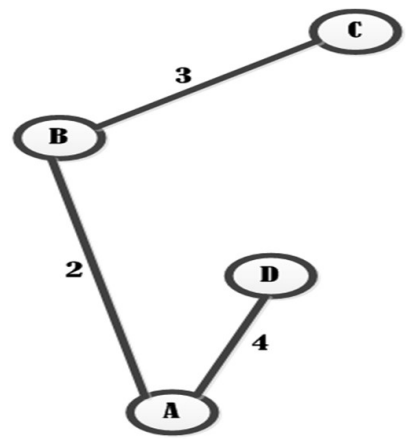

Gambar 3.4. Langkah 4 untuk Gambar 3.1

5. Sisi $D E$ dengan bobot 1 maka spanning tree yang dibentuk adalah

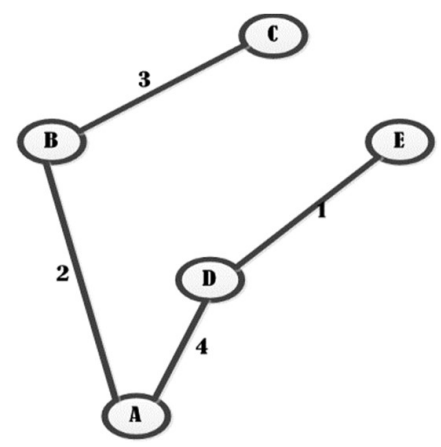

Gambar 3.5. Langkah 5 untuk Gambar 3.1 
6. Sisi $E H$ dengan bobot 2 maka spanning tree yang dibentuk adalah

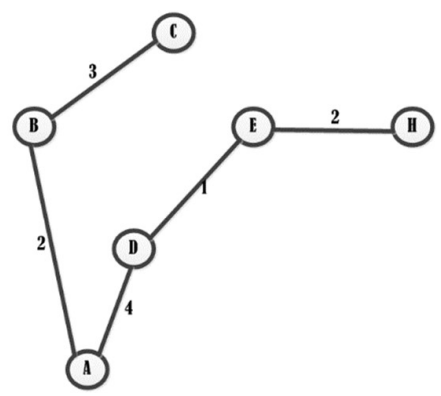

Gambar 3.6. Langkah 6 untuk Gambar 3.1

7. Sisi $H F$ dengan bobot 2 maka spanning tree yang dibentuk adalah

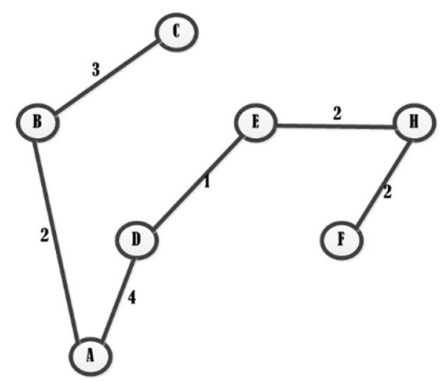

Gambar 3.7. Langkah 7 untuk Gambar 3.1

8. Sisi $F G$ dengan bobot 2 maka spanning tree yang dibentuk adalah

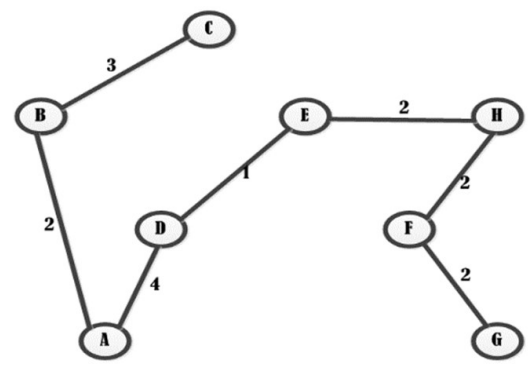

Gambar 3.8. Langkah 8 untuk Gambar 3.1

9. Sisi $G K$ dengan bobot 3 maka spanning tree yang dibentuk adalah

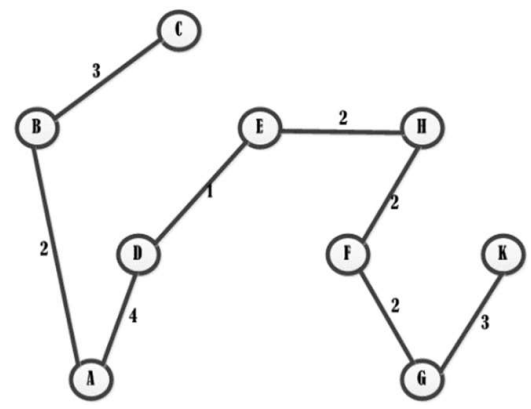

Gambar 3.9. Langkah 9 untuk Gambar 3.1 
10. Sisi $K M$ dengan bobot 3 maka spanning tree yang dibentuk adalah

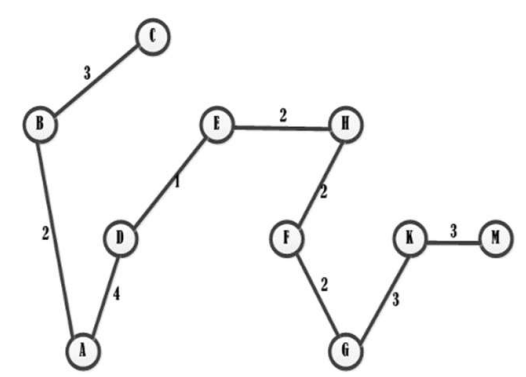

Gambar 3.10. Langkah 10 untuk Gambar 3.1

11. Sisi $M L$ dengan bobot 2 maka spanning tree yang dibentuk adalah

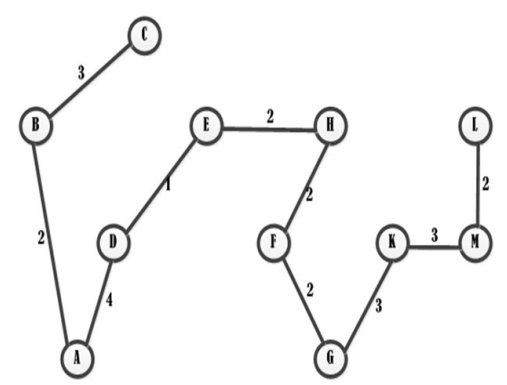

Gambar 3.11 Langkah 11 untuk Gambar 3.1

12. Sisi $L J$ dengan bobot 3 maka spanning tree yang dibentuk adalah

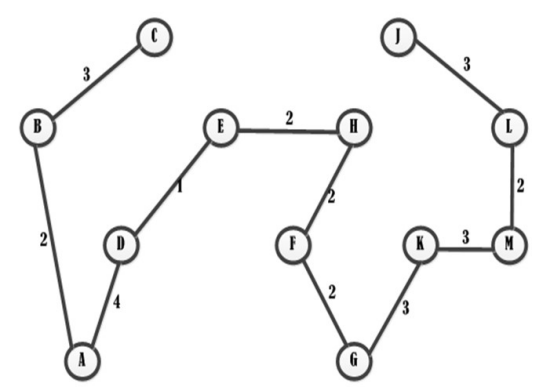

Gambar 3.12. Langkah 12 untuk Gambar 3.1

13. Sisi $J I$ dengan bobot 6 maka spanning tree yang dibentuk adalah

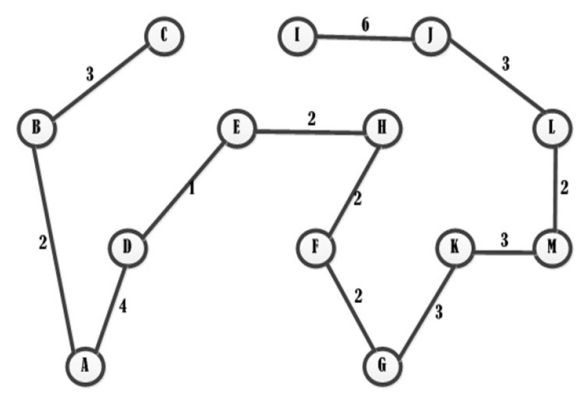

Gambar 3.13. Langkah 13 untuk Gambar 3.1 
Karena semua simpul telah terhubung maka minimum spanning tree yang dihasilkan adalah $3+2+4+1+2+2+2+3+3+2+3+6=33$ dengan model jalur pada Gambar 3.13 .

\section{SIMPULAN}

Pada penelitian ini, dapat disimpulkan bahwa untuk penentuan minimum spanning tree dengan menggunakan algoritma modifikasi dari algoritma Prim dan algoritma Kruskal dalam perencanaan rute wisata dengan konsep hamiltonian path lebih efektif dan efisien.

\section{DAFTAR PUSTAKA}

Changying L, . Liu H,. Liu Y,. Li T dan Wang Tianhao. 2019. Normalized cross correlation image stitching algorithm based on minimum spanning tree, Optik-International Journal for Light and Electron Optics. 179: 610-616

Devi, M. M., dan Geethanjali, M. 2020. Hybrid of Genetic Algorithm and Minimum Spanning Tree method for optimal PMU placements, Measurement. 154: 107476

Didiharyono dan Soraya, Siti. 2018. Penerapan Algoritma Greedy Dalam Menentukan Minimum Spanning Trees Pada Optimisasi Jaringan Listrik Jala, Jurnal Varian, Vol 1, No. 2,1-10

Djafar, Imran dan Abdul Ibrahim. 2011. Implementasi Pohon Merentang Minimum Dalam Menentukan Prioritas Pemeliharaan Jalur Jalan kota Dengan Biaya Minimal, Jurnal Digit, Vol 1, No. 2, 132-142

Nugraha. D. W. 2011. Aplikasi Algoritma Prim untuk Menentukan Minimum Spanning Tree Suatu Graf Berbobot dengan Menggunakan Pemograman Berorientasi Objek, Jurnal Ilmiah Foristek, Vol 1, No. 2, 71.

Rahmawati Anita dan Mulyono. 2015. Minimum Spanning Tree Pada Jaringan Pendistribusian Aneka Kripik Abdi Mulya Di Kabupaten Grobogan, Jurnal UNNES Journal of Mathematics 4 (2): 97-105

Sari, Firar Anitya, Endang Sugiharti dan Dwijanto. 2013. Implementasi Algoritma Genetika untuk Menyelesaikan Itextit\{Travelling Salesman Problem\}, Jurnal UNNES Journal of Mathematics 2 (2): 116-120 